\title{
Antenatal Care Utilization and Pregnancy Outcome in Women Undergoing Emergency Cesarean Section
}

\author{
Zubaida Masood', Samia Husain ${ }^{2 *}$, Rahila Imtiaz ${ }^{1}$ and Rubina Izhar ${ }^{1}$ \\ 'Department of Obstetrics and Gynaecology, Abbasi Shaheed Hospital \& Karachi Medical and Dental College, Karachi, Pakistan \\ ${ }^{2}$ Department of Obstetrics and Gynaecology, Aziz Medical Center, Karachi, Pakistan
}

\begin{abstract}
Objective: To assess the effect of antenatal care utilization on pregnancy outcomes in women undergoing emergency cesarean section.

Methods: This was a retrospective comparative cohort conducted from January to December 2017 at the Department of Obstetrics and Gynaecology, Abbasi Shaheed Hospital, Karachi.. Women who underwent emergency cesarean section were included. Booking status was ascertained from previous antenatal slips. The primary outcome measure was pregnancy outcome, assessed by maternal and fetal parameters. Stay in the hospital for more than 4 days and maternal death were maternal outcomes, whereas neonatal ICU admission and death were fetal outcomes.
\end{abstract}

Results: During the study period, 419 women were delivered by the Emergency cesarean section and were included. Out of these 419 women, $300(71.6 \%)$ were unbooked. Post cesarean, $284(67.8 \%)$ women stayed for four or more days in the hospital and $16(3.8 \%)$ women died. After cesarean section, $87(20.8 \%)$ babies were shifted to neonatal ICU, whereas $91(21.7 \%)$ of the delivered babies died. However, the maternal outcomes (stay of 4 days and above, $p<0.001$ and maternal death, $p=0.045$ ) were significantly worse in unbooked women. Moreover, the fetal outcomes were also poor in the unbooked population (NICU admission, $p=0.004$, and death $p=0.010$ ) as compared to booked women.

Conclusion: Suboptimal antenatal care utilization continues to be an area of concern in Pakistan. Women may need an emergency delivery any time by cesarean section; all efforts must be made to ensure antenatal care is optimized so that high-risk women and those with medical comorbidities do not suffer a suboptimal outcome. A policy that ensures attendance and utilization of antenatal care by all pregnant women is the need of the hour.

Keywords: Antenatal care, cesarean section, pregnancy outcomes.

\section{INTRODUCTION}

Antenatal care provides an excellent opportunity to assess the health of pregnant women and their unborn fetuses before childbirth. It is utilized for screening congenital abnormalities, dating the pregnancy accurately, and triaging women with risk factors like medical disorders who may need special arrangements during pregnancy and labor [1]. Cesarean section is a major abdominal surgery performed when a vaginal birth is considered dangerous for mother, baby, or both. In modern obstetrics, it holds a special place and has rendered childbirth in tricky life-threatening situations safer [2]. However, as it is major surgery it is not devoid of complications. The complications are higher for patients who receive less than optimal prenatal care. Women who are booked at an antenatal facility are less likely to suffer adverse maternal and fetal outcomes [3]. Facility delivery reduces intrapartum complications, but the effect of suboptimal antenatal care remains evident in situations where the parturient requires cesarean delivery [4]. According to a survey, women from low and middle-income countries are more likely to underutilize

*Corresponding Author: Samia Husain, Department of Obstetrics and Gynaecology, Aziz Medical Center, Karachi, Pakistan

Email: samiahusain_scorpio@hotmail.com

Received: June 05, 2020; Revised: July 08, 2020; Accepted: July 27, 2020

DOI: https://doi.org/10.37184/lnjpc.2707-3521.2.3 antenatal care and present in the unbooked state at later gestations [5]. In a study from Bangladesh, the authors concluded that antenatal care coverage is poor in the region both in terms of the number of visits and their content [6]. Pakistan is also a developing country where antenatal care though available is not utilized and affects fetomaternal outcomes [7]. According to the study of Adekanle et al., unbooked women having cesarean sections are more prone to adverse fetomaternal outcomes than booked mothers [8]. Several studies have assessed the effect of antenatal care utilization but data on antenatal care utilization in women who subsequently undergo cesarean section and the morbidity they encounter remains deficient. We undertook this study to assess the effect of antenatal care utilization on pregnancy outcomes in women undergoing emergency cesarean section at a tertiary care facility.

\section{METHODS}

This was a retrospective comparative cohort study conducted at the Department of Obstetrics and Gynaecology, Abbasi Shaheed Hospital, Karachi, from $1^{\text {st }}$ January 2017 to $31^{\text {st }}$ December 2017. Consent for use of hospital records was taken from the unit head. Case records were compiled and analyzed. The labor room records from January to December of the year were used. Cesarean section rate of the year was 
calculated by including all women delivering at the unit during the study period. Thereafter, women who underwent emergency cesarean section were included. Excluded from the analysis were women who had cesarean elsewhere and were shifted post-cesarean due to complications. Booking status was ascertained from previous antenatal slips. A case was considered booked if she was seen at the antenatal clinic four or more times. Routine unit policy for antenatal tests and ultrasound scans was also ensured. Supplementation of iron and calcium was also checked on all slips. A proforma was filled. It included a woman's age, gestational age of the fetus at presentation, and her parity. The outcome of pregnancy included maternal and fetal parameters; stay in hospital more than 4 days and maternal death were maternal outcome parameters, whereas neonatal ICU admission and neonatal death were included as fetal outcome parameters in proforma.

Data was entered and analyzed using SPSS version 15. Shapiro-Wilk test was used to assess the normality of data distribution. Variables such as gestational age and age were recoded into categories. The gestational age ranges were as follows: less than 34 weeks, 34-36 + 6 weeks, 37 weeks, and above. Age ranges were as follows: $\leq 19$ years, 20-24 years, 25-29 years, 30-34 years, and $\geq 35$ years. Frequency and percentages were calculated for qualitative variables such as age range, gestational age range, parity, booking status, stay in hospital of woman, death of woman, NICU admission, and death of a baby. Effect modifiers were controlled through stratification of women's age, gestational age, and parity to identify their effects on the outcome variables. The post-stratification chi-square test was used with $p$-value $\leq 0.05$ considered statistically significant.

\section{RESULTS}

In the year 2017, 1411 deliveries took place in the unit. Out of these 1411, 512 were delivered by cesarean section at the unit and were included. The cesarean section rate was $36.28 \%$ for the year. Of these 419 were emergency cesarean sections and were included. Most women ( $n=166,39.6 \%)$ were of ages 20-24 years, were 37 weeks or more pregnant $(n=311$, $74.2 \%)$ and had less than 3 children ( $n=283,67.5 \%)$. Table 1 summarizes the characteristics of the study population.

Of these 419 women, 300 (71.6\%) were unbooked. Post cesarean, $284(67.8 \%)$ stayed four or more days in the hospital, and $16(3.8 \%)$ of those who were operated died. Out of these 16, 14(87.5\%) were direct maternal deaths and $2(12.5 \%)$ were indirect maternal deaths. Of the direct maternal deaths, $7(50 \%)$ had antepartum hemorrhage due to abruption, they subsequently went into DIC (disseminated intravascular coagulation), 4(28.6\%) women had eclampsia, 2(14.3\%) died due to sepsis while $1(7.1 \%)$ woman died due to uterine rupture secondary to obstructed labor. Both indirect maternal deaths were due to cardiac diseases. One patient had Eisenmenger syndrome and the other patient had mitral stenosis.

After cesarean section, 87 (20.8\%) neonates were shifted to neonatal ICU, whereas $91(21.7 \%)$ of the delivered babies died. A pediatrician received all babies and assessed them. Babies were admitted to NICU on the pediatrician's advice. In our study, all admissions to NICU were due to respiratory distress.

The booked mothers were similar to unbooked mothers in terms of age, gestational age at presentation, and parity. However, the maternal outcomes (stay of 4 days and above, $p<0.001$ and maternal death, $p=0.049$ ) were significantly worse in unbooked women. Moreover, the fetal outcomes were also poor in the unbooked population (NICU admission, $p=0.004$, and death $p=0.010$ ) as compared to booked women (Table 1).

Table 1: Comparison of booked and unbooked women.

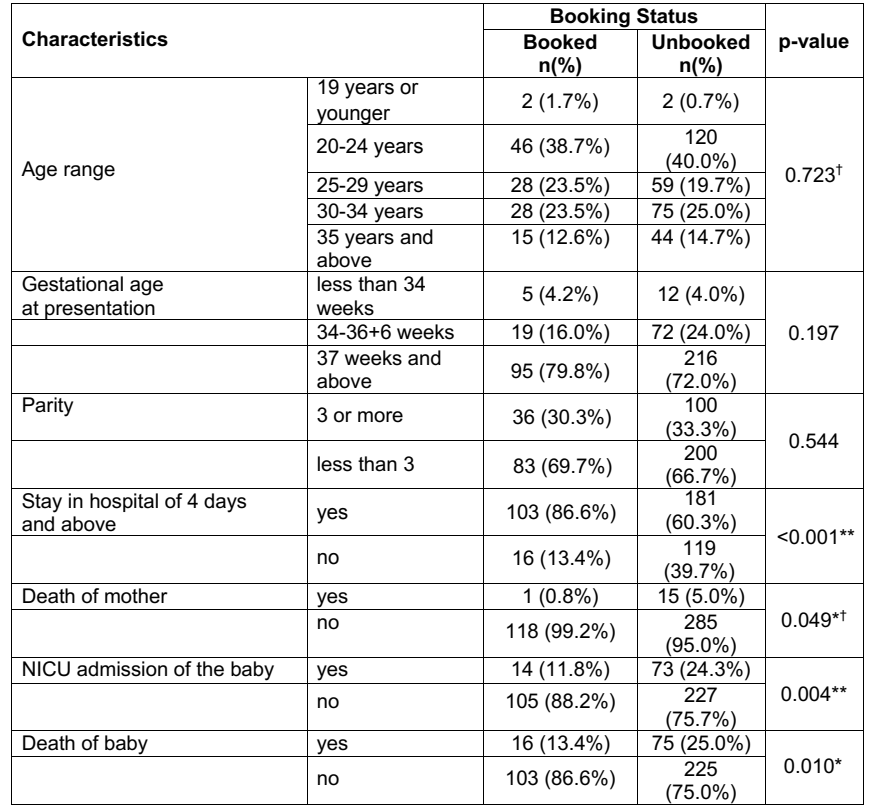

*denotes significance at $p<0.05$; **denotes significant at $p<0.01$ level; $t$ denotes the Fisher-exact test was applied.

The maternal outcome differed significantly according to age, parity, and gestational age at presentation of women (Table 2).

Maternal death was significantly higher in older women $(p<0.001)$ and women of higher parity $(p=0.038)$, whereas stay of more than 4 days was significantly common at lower gestations $(p<0.001)$. 
Table 2: Maternal outcome stratified by characteristics.

\begin{tabular}{|c|c|c|c|c|c|c|c|}
\hline \multicolumn{2}{|c|}{-} & \multicolumn{6}{|c|}{ Maternal Outcomes } \\
\hline \multicolumn{2}{|c|}{ Characteristics } & \multicolumn{3}{|c|}{$\begin{array}{c}\text { Stay in Hospital of } 4 \text { Days and } \\
\text { Above }\end{array}$} & \multicolumn{3}{|c|}{ Death of Mother } \\
\hline \multicolumn{2}{|c|}{-} & $\begin{array}{l}\text { Yes } \\
\mathrm{n}(\%)\end{array}$ & $\begin{array}{c}\text { No } \\
\mathrm{n}(\%)\end{array}$ & $p$-value & $\begin{array}{l}\text { Yes } \\
\text { n(\%) }\end{array}$ & $\begin{array}{c}\text { No } \\
\mathrm{n}(\%)\end{array}$ & $p$-value \\
\hline \multirow{5}{*}{ Age range } & $\begin{array}{l}\text { less than } 19 \\
\text { years }\end{array}$ & $\begin{array}{c}0 \\
(0.0 \%)\end{array}$ & $\begin{array}{c}4 \\
(1.4 \%)\end{array}$ & \multirow{5}{*}{$0.541^{\dagger}$} & $\begin{array}{c}0 \\
(0.0 \%)\end{array}$ & $\begin{array}{c}4 \\
(1.0 \%)\end{array}$ & \multirow{5}{*}{$<\underset{\dagger}{<0.001^{* *}}$} \\
\hline & $20-24$ & $\begin{array}{c}60 \\
(44.4 \%)\end{array}$ & $\begin{array}{c}106 \\
(37.3 \%)\end{array}$ & & $\begin{array}{c}0 \\
(0.0 \%)\end{array}$ & $\begin{array}{c}166 \\
(41.2 \%)\end{array}$ & \\
\hline & $25-29$ years & $\begin{array}{c}26 \\
(19.3 \%)\end{array}$ & $\begin{array}{c}61 \\
(21.5 \%)\end{array}$ & & $\begin{array}{c}2 \\
(12.5 \%)\end{array}$ & $\begin{array}{c}85 \\
(21.1 \%)\end{array}$ & \\
\hline & $30-34$ years & $\begin{array}{c}32 \\
(23.7 \%)\end{array}$ & $\begin{array}{c}71 \\
(25.0 \%)\end{array}$ & & $\begin{array}{c}7 \\
(43.8 \%)\end{array}$ & $\begin{array}{c}96 \\
(23.8 \%)\end{array}$ & \\
\hline & $\begin{array}{l}35 \text { years and } \\
\text { above }\end{array}$ & $\begin{array}{c}17.170 \\
(12.6 \%)\end{array}$ & $\begin{array}{c}42 \\
42.0 \%)\end{array}$ & & $\begin{array}{l}\frac{75.0 \%)}{7} \\
(43.8 \%)\end{array}$ & $\begin{array}{c}\frac{50}{52} \\
(12.9 \%)\end{array}$ & \\
\hline \multirow{3}{*}{$\begin{array}{l}\text { Gestational age } \\
\text { at presentation }\end{array}$} & $\begin{array}{l}\text { less than } 34 \\
\text { weeks }\end{array}$ & $\begin{array}{c}9 \\
(6.7 \%)\end{array}$ & $\begin{array}{c}8 \\
(2.8 \%)\end{array}$ & \multirow{3}{*}{$<\underset{*}{<001 t^{*}}$} & $\begin{array}{c}0 \\
(0.0 \%)\end{array}$ & $\begin{array}{c}17 \\
(4.2 \%)\end{array}$ & \multirow{3}{*}{$0.318^{\dagger}$} \\
\hline & $\begin{array}{l}34-36+6 \\
\text { weeks }\end{array}$ & $\begin{array}{c}46 \\
(34.1 \%)\end{array}$ & $\begin{array}{c}45 \\
(15.8 \%)\end{array}$ & & $\begin{array}{c}6 \\
(37.5 \%)\end{array}$ & $\begin{array}{c}85 \\
(21.1 \%)\end{array}$ & \\
\hline & $\begin{array}{l}37 \text { weeks } \\
\text { and above }\end{array}$ & $\begin{array}{c}80 \\
(59.3 \%)\end{array}$ & $\begin{array}{c}231 \\
(81.3 \%)\end{array}$ & & $\begin{array}{c}10 \\
(62.5 \%)\end{array}$ & $\begin{array}{c}301 \\
(74.7 \%)\end{array}$ & \\
\hline \multirow{2}{*}{ Parity } & 3 or more & $\begin{array}{c}38 \\
(28.1 \%)\end{array}$ & $\begin{array}{c}98 \\
(34.5 \%)\end{array}$ & \multirow{2}{*}{0.194} & $\begin{array}{c}9 \\
96.3 \%)\end{array}$ & $\begin{array}{c}127 \\
(31.5 \%)\end{array}$ & \multirow{2}{*}{$0.038^{*}$} \\
\hline & less than 3 & $\begin{array}{c}97 \\
(71.9 \%)\end{array}$ & $\begin{array}{c}186 \\
(65.5 \%)\end{array}$ & & $\begin{array}{c}7 \\
(43.8 \%)\end{array}$ & $\begin{array}{c}276 \\
(68.5 \%)\end{array}$ & \\
\hline
\end{tabular}

${ }^{*}$ denotes significance at $p<0.05 ;{ }^{* *}$ denotes significant at $p<0.01$ level; $\nmid$ denotes the Fisher-exact test was applied.

The fetal outcomes also showed significant differences in terms of parity and gestational age at presentation (Table 3).

Table 3: Fetal outcome stratified by characteristics.

\begin{tabular}{|c|c|c|c|c|c|c|c|}
\hline \multirow{3}{*}{\multicolumn{2}{|c|}{ Characteristics }} & \multicolumn{6}{|c|}{ Fetal Outcomes } \\
\hline & & \multicolumn{3}{|c|}{ NICU Admission of Baby } & \multicolumn{3}{|c|}{ Death of Baby } \\
\hline & & $\begin{array}{l}\text { Yes } \\
\mathrm{n}(\%)\end{array}$ & $\begin{array}{c}\text { No } \\
\mathrm{n}(\%)\end{array}$ & p-value & $\begin{array}{l}\text { Yes } \\
\mathrm{n}(\%)\end{array}$ & $\begin{array}{c}\text { No } \\
\mathrm{n}(\%)\end{array}$ & $p$-value \\
\hline \multirow{5}{*}{ Age } & $\begin{array}{l}\text { less than } \\
19 \text { years }\end{array}$ & $0(0.0)$ & $4(1.20)$ & \multirow{5}{*}{$0.565^{\dagger}$} & $0(0.0)$ & $4(1.20)$ & \multirow{5}{*}{$0.722^{\dagger}$} \\
\hline & $20-24$ & $36(41.4)$ & $\begin{array}{c}130 \\
(39.2)\end{array}$ & & $35(38.5)$ & $\begin{array}{c}131 \\
(39.9)\end{array}$ & \\
\hline & $\begin{array}{l}25-29 \\
\text { years }\end{array}$ & $15(17.2)$ & $72(21.7)$ & & $16(17.6)$ & $71(21.6)$ & \\
\hline & $\begin{array}{l}30-34 \\
\text { years }\end{array}$ & $26(29.9)$ & $77(23.2)$ & & $26(28.6)$ & 77 (23.5) & \\
\hline & $\begin{array}{c}35 \text { years } \\
\text { and above }\end{array}$ & $10(11.5)$ & $49(14.8)$ & & $14(15.4)$ & $45(13.7)$ & \\
\hline \multirow{3}{*}{$\begin{array}{c}\text { Gestatio } \\
\text { nal age } \\
\text { at } \\
\text { presenta } \\
\text { tion }\end{array}$} & $\begin{array}{l}\text { less than } \\
34 \text { weeks }\end{array}$ & $13(14.9)$ & $4(1.2)$ & \multirow{3}{*}{$<\underset{\dagger}{<0.001^{* *}}$} & $14(15.4)$ & $3(0.9)$ & \multirow{3}{*}{$<0.001^{\star \star \dagger}$} \\
\hline & $\begin{array}{c}\begin{array}{c}34-36+6 \\
\text { weeks }\end{array} \\
\end{array}$ & $66(75.9)$ & $25(7.5)$ & & $68(74.7)$ & $23(7.0)$ & \\
\hline & $\begin{array}{l}37 \text { weeks } \\
\text { and above }\end{array}$ & $8(9.2)$ & $\begin{array}{c}303 \\
(91.3)\end{array}$ & & $9(9.9)$ & $\begin{array}{c}302 \\
(92.1)\end{array}$ & \\
\hline \multirow{2}{*}{ Parity } & 3 or more & $16(18.4)$ & $\begin{array}{c}120 \\
(36.1)\end{array}$ & \multirow{2}{*}{$0.002^{\star \star}$} & $16(17.6)$ & $\begin{array}{c}120 \\
(36.6)\end{array}$ & \multirow{2}{*}{$0.001^{\star *}$} \\
\hline & $\begin{array}{c}\text { less than } \\
3\end{array}$ & 71 (81.6) & $\begin{array}{c}212 \\
(63.9)\end{array}$ & & $75(82.4)$ & $\begin{array}{c}208 \\
(63.4)\end{array}$ & \\
\hline
\end{tabular}

*denotes significance at $p<0.05 ;{ }^{* *}$ denotes significant at $p<0.01$ level; tdenotes Fisher-exact test was applied.

\section{DISCUSSION}

The present study evaluates the effect of antenatal care utilization on maternal and fetal outcomes of women undergoing cesarean section at a tertiary facility. Our study depicts that booked mothers are less likely to face adverse fetomaternal outcomes than unbooked mothers.

The number of maternal deaths and stay in hospitals is lower for booked women. When stratified according to parity, age, and gestational age at the presentation the maternal outcomes were significant for older, parous women who presented for delivery at the facility.

The death of a baby and neonatal ICU admissions are also lower for booked mothers. The neonatal ICU admissions and deaths remained significantly higher for women with lower gestation at delivery and higher parity.

\section{INTERPRETATION}

Antenatal care is the cornerstone of safe motherhood. WHO/UNICEF report 2003, recommended that women should present at an antenatal care facility at least 4 times during each pregnancy [9]. The impact of prenatal care in minimizing and preventing adverse fetomaternal outcome is profound.

The role of good antenatal care in both simple and complicated cases is well- documented. The attendance at antenatal care clinics has improved considerably in the country but the required level has still not been achieved. Only $37 \%$ of women receive at least 4 antenatal visits in the country [10]. Only $28.4 \%$ of the women in our study were booked. This underutilization of antenatal care is alarming. Our study shows that despite availability, the service is not utilized though the facility is maintained by the local government and provides consultation free of cost.

The study shows that most women having a cesarean at the facility are unbooked $(71.6 \%)$. Most of these women suffer adverse fetomaternal outcome and the dictum facility delivery reduces complications fails to hold in these cases. Similar findings were reported from Ethiopia where only $56 \%$ of women who attend a minimum of 4 visits deliver at the facility [11]. Most of the women who deliver at the facility are either unbooked or are brought after a trial at home and need emergency delivery [4].

Unbooked mothers and their babies are at higher risk of adverse fetomaternal outcomes. In our analysis maternal death and neonatal death occurred in unbooked patients. Maternal death was also significantly higher in women of advanced maternal age $(p<0.001)$ and higher parity $(p=0.038)$. Cesarean delivery is an added risk factor for these high-risk groups. Advanced maternal age, prior comorbid, and obesity are commonly quoted risk factors for adverse outcomes in women undergoing cesarean section [12].

Stay in the hospital for more than 4 days is considered an adverse outcome and is associated with maternal morbidity. Longer stay not only signals increased risk of hospital-acquired infections but disruption of daily life activities. Cases of prolonged stay after cesarean section are mostly due to uncontrolled antenatal factors or complications that arise intrapartum. These could be controlled and complications reduced if women present for proper antenatal care [13, 14].

Promoting antenatal care and good intrapartum care are recommended to improve neonatal survival. The most commonly documented problems for NICU admissions are sepsis, respiratory distress, and 
congenital abnormalities [15]. In our study, more neonates of unbooked mothers $(24.3 \%$ vs. $11.8 \%)$ were admitted to NICU, and neonatal deaths $(25 \%$ vs. $13.4 \%$ ) were also common in those with suboptimal antenatal care.

Gestational age at presentation was also significantly associated with adverse neonatal outcomes in our analysis. Lower gestational age at cesarean predisposes to respiratory morbidity that can be prevented to a great extent by the timely administration of steroids [16]. Also, congenital malformations can be picked up at the anomaly scan and appropriate counseling and mobilization of resources can take place to ensure a better outcome [17]. In our study booked and unbooked women were not significantly different in terms of gestational age (Table 2 ). But when stratified for gestational age, (Table 3) women with lower gestational age had significantly higher neonatal deaths and neonatal ICU admissions. An opportunity was thus missed in these women. And as more unbooked women were present in the analysis, the role of appropriate antenatal care in this population cannot be emphasized enough.

\section{CONCLUSION}

Suboptimal antenatal care utilization continues to be an area of concern in Pakistan. Women may need an emergency delivery any time by cesarean section; all efforts must be made to ensure antenatal care is optimized so that high-risk women and those with medical comorbidities do not suffer a suboptimal outcome. A policy that ensures attendance and utilization of antenatal care by all pregnant women is the need of the hour.

\section{STRENGTHS AND LIMITATIONS}

The strength of this study is its large sample size and data from a single center. Our study utilized the case records and recall bias was minimized. Outcomes were standardized and a tertiary care facility was targeted to assess the antenatal care utilization by the general public.

The retrospective data collection is a major limitation and therefore affects certain parameters that could have been included. Parameters such as maternal anemia and subsequent need for blood transfusion affect the maternal outcome. In our study 14 direct and 2 indirect maternal deaths occurred which could have been avoided or outcomes could have been improved if better utilization of antenatal care was ensured in these women.

\section{ETHICAL APPROVAL}

The study used data records of the patients who underwent cesarean section. Retrospective data was used in the study. Instead of a formal ethics committee approval, the principles of the Helsinki's Declaration were followed. Data was coded and confidentiality was ensured. The Head of the department granted permission for the study.

\section{CONFLICT OF INTEREST}

The authors declare no conflict of interest.

\section{FUNDING}

None.

\section{ACKNOWLEDGEMENTS}

None.

\section{REFERENCES}

1. Moller AB, Petzold M, Chou D, Say L. Early antenatal care visit: a systematic analysis of regional and global levels and trends of coverage from 1990 to 2013. Lancet Glob Health 2017; 5(10): e977-e983.

2. Ugwa E, Ashimi A, Abubakar MY. Caesarean section and perinatal outcomes in a sub-urban tertiary hospital in North-West Nigeria. Niger Med J 2015; 56(3): 180-4.

3. Pokharel HP, Lama GJ, Banerjee B, Paudel LS, Pokharel PK. Maternal and perinatal outcome among the booked and unbooked pregnancies from catchments area of BP Koirala Institute of Health Sciences, Nepal. Kathmandu Univ Med J (KUMJ) 2007; 5(2): 173-6.

4. Khanam R, Baqui AH, Syed MIM, Harrison M, Begum N, Quaiyum $\mathrm{A}$, et al. Can facility delivery reduce the risk of intrapartum complications-related perinatal mortality? Findings from a cohort study. J Glob Health 2018; 8(1): 010408.

5. Saad-Haddad G, De Jong J, Terreri N, Restrepo-Méndez MC, Perin J, Vaz L, et al. Patterns and determinants of antenatal care utilization: analysis of national survey data in seven countdown countries. J Glob Health 2016; 6(1): 010404.

6. Siddique $A B$, Perkins J, Mazumder T, Haider MR, Banik G, Tahsina $\mathrm{T}$, et al. Antenatal care in rural Bangladesh: gaps in adequate coverage and content. PLoS One 2018; 13(11): e0205149.

7. Ali Khan RE, Ahmad TI, Noreen S, Ejaz A. Quantity of prenatal care (PNC) services use in Southern Punjab: a case study of Bahawalpur. J Pak Med Assoc 2019; 69(1): 64-7.

8. Adekanle DA, Adeyemi AS, Fadero FF. Booking status and caesarean section outcome in LAUTECH teaching Hospital, Osogbo. Niger J Med 2008; 17(1): 25-8.

9. WHO. Antenatal care in developing countries: premises, achievements and missed opportunities. Available at: https://www.who.int/reproductivehealth/publications/ maternal_perinatal_health/9241590947/en/.

10. Nisar YB, Aurangzeb B, Dibley MJ, Alam A. Qualitative exploration of facilitating factors and barriers to use of antenatal care services by pregnant women in urban and rural settings in Pakistan. BMC Pregnancy Childb 2016; 16: 42. 
11. Fekadu GA, Ambaw F, Kidanie SA. Facility delivery and postnatal care services use among mothers who attended four or more antenatal care visits in Ethiopia: further analysis of the 2016 demographic and health survey. BMC Pregnancy Childb 2019; 19(1): 64 .

12. Leonard SA, Main EK, Carmichael SL. The contribution of maternal characteristics and cesarean delivery to an increasing trend of severe maternal morbidity. BMC Pregnancy Childb 2019; 19(1): 16.

13. Walker AR, Waites BT, Caughey AB. The impact of extremes of maternal age on maternal and neonatal pregnancy outcomes in women with pregestational diabetes mellitus. J Matern Fetal Neonatal Med 2018; 13: 1-5.

14. Rymer-Haskel N, Schushan-Eisen I, Hass Y, Rahav R, Maayan-Metzger A, Hendler I. Characteristics and severity of preeclampsia in young and elderly gravidas with hypertensive disease. Eur J Obstet Gynecol Reprod Biol 2018; 228: 120-5.

15. Orsido TT, Asseffa NA, Berheto TM. Predictors of neonatal mortality in neonatal intensive care unit at referral Hospital in Southern Ethiopia: a retrospective cohort study. BMC Pregnancy Childb 2019; 19(1): 83.

16. Roberts D, Brown J, Medley N, Dalziel SR. Antenatal corticosteroids for accelerating fetal lung maturation for women at risk of preterm birth. Cochrane Database Syst Rev 2017; 3: CD004454.

17. Wood SL, Owen J, Jenkins SM, Harper LM. The utility of repeat midtrimester anatomy ultrasound for anomaly detection. Am J Perinatol 2018; 35(14): 1346-51. 